\title{
Empowering Society through Knowledge Records
}

\author{
Meliha Handzic \\ School of Information Systems, Technology and Management \\ The University of New South Wales, Sydney 2052, Australia \\ m.handzic@unsw.edu.au
}

\begin{abstract}
This paper focuses on the role of knowledge records in helping governments to achieve a wiser and fairer society. It presents a view of knowledge records as society's tools for establishing evidence, protecting human rights, supporting the rule of law, and preserving cultural capital. It also discusses the issues of quality and integrity of knowledge records, and suggests a plausible method to direct the development and implementation of proper knowledge records management systems in government agencies.
\end{abstract}

\section{Introduction}

Our current understanding of the level of penetration and impact of knowledge management initiatives in non-profit organizations, including government, is very limited. Preliminary empirical evidence from Australia reveals a relatively high level of awareness, combined with a low level of implementation of knowledge management in academia [8]; some promotional activities related to the creation of knowledge-enabled environments in major government agencies [20]; and initial efforts focused on delivering better electronic government services to the public [12].

So far, Australian federal agencies have been successful in implementing an initial "Government Online" strategy which ensured that all appropriate information and services are now available via the internet for those wanting to access them. "Better Service, Better Government" is a new strategy that maps out the next phase in the federal government's drive to move on from placing information and services on-line. Key objectives include greater efficiency, convenient access to services, better service delivery, integration of related services, building of user trust and confidence, and enhanced citizen engagements or "e-democracy".

This paper focuses on the role played by knowledge management, particularly the process of capturing and preserving society's knowledge, in helping governments ensure fairer and wiser society.

\section{The Concept of Knowledge Record}

The term "knowledge record" is a derivative of two terms: "knowledge" and "record". The word record denotes any kind of recording that is created and kept as part of conducting individual or institutional affairs. There is no one agreed definition of

The original version of this chapter was revised: The copyright line was incorrect. This has been corrected. The Erratum to this chapter is available at DOI: 10.1007/978-3-540-44836-5_33

M.A. Wimmer (Ed.): KMGov 2003, LNAI 2645, pp. 262-267, 2003.

(C) Springer-Verlag Berlin Heidelberg 2003 
knowledge. Rather, knowledge is defined differently from different philosophical perspectives. From the cognitive perspective, for example, knowledge is perceived as externally justified beliefs, based on formal models, universal and explicit, that operate through cognitive processes. On the other hand, from the constructivist perspective, knowledge is viewed as acts of construction or creation, creative arts, not universal, beliefs that depend on personal sense making [23]. Often, knowledge is defined in terms of relationships between data and information.

In theory, knowledge is described as deeper and richer information [3]; information combined with experience, context, interpretation and reflection [4]; valuable information in action [6]; and information that has been internalised by a person to the degree that he or she can make use of it [5]. However, in practice, the terms data, information and knowledge are often used interchangeably [10].

Based on Polanyi's [16] original work, knowledge is usually classified as either explicit or tacit [13], [14]. Explicit knowledge is described as formal, systematic knowledge that can be expressed or communicated without vagueness or ambiguity. It can be stored in books, manuals, databases and in other ways. Tacit knowledge, on the other hand, is considered as highly personal know-how that is derived from experience and beliefs and usually hard to articulate and communicate. Such knowledge exists in the individual minds of people.

Some taxonomies make a distinction between declarative, procedural, inferential and motivational forms of professional knowledge [17], as well as conditional, relational and pragmatic types [1]. Other schemes recognise individual and artifact loci, varying degrees of knowledge structure, and individual and collective levels of knowledge [7]. A pragmatic approach to classifying knowledge simply attempts to identify knowledge useful to stakeholders. Recognising knowledge as a complex and multifaceted concept, the objective of this paper is to take a closer look at one specific facet: explicit recorded knowledge, created in the conduct of society's affairs.

\section{How Knowledge Records Empower Society}

Individuals, groups and societies treat their knowledge in different ways. Eastern cultures seem to value more "tacit" knowledge that is kept in people's heads and transferred through socialisation. Western cultures, on the other hand, appear to focus more on "explicit" knowledge, captured and preserved in collective and codified repositories [14]. Based on this distinction, a widely adopted broad classification of knowledge management strategies comprises two classes: personalisation and codification [9]. The personalisation strategy assumes that tacit knowledge is shared through interpersonal communication. Codification assumes that knowledge can be effectively extracted and codified. In this approach, knowledge artifacts are stored and indexed in databases for later retrieval and use. As such, it can serve as evidence and proof of an idea, decision or action taken by either an individual, organisation or government.

Following the principles of codification, a comprehensive framework for building a society's cumulative "explicit" knowledge base has been proposed [15]. This framework suggests that the process starts with identifying critical documentable knowledge. This may include individual and group ideas, actions, decisions and 
transactions worth preserving. Once identified as such, these documentable "acts" are then codified, organised, stored and kept together with relevant meta-knowledge for as long as required. Typically, only a small portion of recorded knowledge has long term significance and becomes part of the society's cumulative memory and of concern to public authorities. Pederson [15] provides numerous examples of such knowledge records from the worlds' public archives available on the internet. The following paragraphs summarise and illustrate a number of representative Australian cases.

Example 1. Accumulated knowledge records can be viewed as an important societal tool for establishing facts and a way to validate human memory. Typically, they include personal documents; corporate knowledge bases; industry and government reports and statistics; technical and specialist literature; databases and internet resources; academic journals; scholarly and reference books; general knowledge compilations; popular books and magazines; and info-tainment. Founding Documents is one example of an important Australian project in social history realised as a partnership of eight government archives for the Centenary of Federation celebration. The project is available at http://www.foundingdocs.gov.au/.

Example 2. Knowledge records are also important in ensuring the protection of individual rights. Personal records are especially crucial to individuals seeking to establish their identity and ensure their entitlements. The intentional destruction of one's vital personal records can be extremely disruptive and often life threatening to those affected. The stories of Kosovars found at web pages of the United Nations High Commissioner for Refugees, and various government councils give a graphic insight into the experiences and deprivation suffered by people whose identity documents were systematically destroyed and who were forced to become refugees. Australian Government provides instruction and help to refugees through Refugee Council of Australia available at http://www.refugeecouncil.org.au/.

Example 3. Progressive societies demand that governments and individuals demonstrate great responsibility and accountability in the conduct of their public and personal affairs. Typically, governments enact laws and regulations that define the structures and sets of rules governing the relations and activities of all legal entities within their jurisdictions. Despite this, keeping those in charge honest still represents a major challenge for democratic societies. The Australian Government has recently awarded a major research grant to the Records Continuum Research Group, at Monash University to investigate the issue of accountability in public services. Their web site at http://rcrg.dstc.edu.au/publications/recordscontinuum/smoking.html contains numerous reports and analyses of recent crises, scandals and risks faced by the Australian public sector that all have their roots in inadequate knowledge records management.

Example 4. The capacity to construct and transfer culture has always been considered as an essential social function. Recorded knowledge has an important cultural value too. It links us to the ideas and activities that have lasting importance for symbolic or concrete reasons. Bodies of recorded knowledge constitute a society's "cultural capital". Cumulative layers of evidence legitimise and witness the development of significant ideas and activities within a society over time. One of the recent Australian 
contributions to preserving society's achievements is Bright Sparcs, available at http://www.asap.unimelb.edu.au/bsparcs/bsparcshome.htm. It is a register of over 3,000 people involved in the development of science, technology and medicine in Australia. The site also includes references to scientists' materials and resources

\section{Issues in Knowledge Records Management}

Because of the power of recorded knowledge as a resource of wisdom and justice in society, knowledge management must ensure that government's knowledge repositories are of high quality and integrity and also ensure their availability to the right people, at the right time, and in the right form.

Different perspectives on quality are provided by different proposed frameworks. Shanks and Tansley [19] define quality in terms of "fitness for purpose". Others consider accuracy, reliability, importance, consistency, precision, timeliness, understandability, conciseness and usefulness as desirable quality dimensions [2], [24]. The framework by Strong et al. [22], suggests four quality dimensions: intrinsic, contextual, representational and accessibility. The framework of Shanks and Darke [18] consists of syntactic, semantic, pragmatic and social quality goals and measures for stakeholders. Other frameworks include Wand and Wang [24], based on Bunge's ontology, and Kahn et al. [11], which is based on product and service quality theory.

The Australian standard for knowledge records management [21] lists several important characteristics that records should have in order to ensure society's need for evidence, accountability and information. First of all, a record's content should correctly reflect an idea that was communicated, or a decision that was made, or an action that was taken. As well as the content, the record should also contain metadata describing its structure, context and links to relevant other records. Furthermore, the record should be authenticated, that is proven to be what it purports to be, shown to have been created or sent by the person purported to have created or sent it, and verified as having been created or sent at the time purported. The record should also be reliable, so that its contents can be trusted as a complete and accurate representation of knowledge. The integrity of a record should be preserved by protection from unauthorized alteration. Finally, it should be useable, easy to locate, retrieve, present and interpret.

The failure to address the issues of quality and integrity of records in a government's knowledge repositories may lead to serious impairment of functioning of society and its institutions, the loss of evidence of the rights of people as citizens, the inability of societal watchdogs to call to account governments and individuals, the loss of collective and individual identity and memory, and the inability to authenticate and source critical knowledge. These issues pose a great challenge to governments.

\section{Australian Standard Guidelines}

The Australian Records Management Standard provides a methodology that specifically aims at facilitating the implementation of knowledge records management systems [21]. One of its first recommendations is to define and document relevant 
policies. A policy statement can be understood as a statement of intentions. It also sets out programmes and procedures to support those intentions. Then, the standard describes a step-by-step procedure for designing and implementing records systems, that includes preliminary investigation, analysis of activities, identification of requirements, assessment of existing systems, identification of strategies, systems design, systems implementation and post-implementation review.

Another Standard recommendation specifies required operational processes and controls. Theoretically, these processes include a linear sequence of capture, registration, record classification, access and security classification, identification of disposition status, storage, use and tracking, and implementation of disposal activities. However, in practice, some operations may take place simultaneously. Certain operations may depend on the existence of controls. Controls include the instruments needed for different operations, and factors that may affect these operations. The principal instruments include classification schemes, the disposition authority, and the security and access scheme. Additional ones include specific tools such as a thesaurus and a glossary of terms, as well as regulatory and risk frameworks, formalised delegation of authority and the registry of permissions.

Finally, the standard specifies the need to define responsibilities and authorities. The overriding objective of this recommendation is to establish and maintain the regime that meets the needs of all stakeholders. The likely authorities and responsibilities of senior managers include ensuring the success of the overall knowledge records management programme. Specialised professionals have primary responsibility for the implementation of policies, procedures and standards. Other knowledge workers may have a variety of specific duties, including responsibility for security, responsibility for design and implementation of information and communication technology based systems, or creation, receipt and storage of knowledge records.

\section{Conclusions}

This paper addresses the role of knowledge records in empowering society. In summary, it identifies accumulated knowledge records as important societal tools for establishing facts, and a way to validate human memory, protect human rights, support the rule of law, and preserve culture. It also recognizes the need for high quality and integrity within the knowledge records in government repositories, as well as allowing availability to the right people, at the right time, and in the right form. Finally, guidelines for developing and implementing knowledge records management systems that comply with the best national practices are outlined.

\section{References}

1. Alavi, M., Leidner, D.E.: Knowledge Management and Knowledge Management Systems: Conceptual Foundations and Research Issues. MIS Quarterly, 1 (2001) 107-136

2. Ballou, D.P., Pazer H.L.: Modeling data and process quality multi-input multi-output information systems. Management Science. 2 (1985) 150-162 
3. Davenport, T.H., Prusak L.: Working Knowledge. Harvard Business School Press, Boston (1998)

4. Davenport, T.H., DeLong, D.W., Breers, M.C.: Successful Knowledge Management Projects. Sloan Management Review, Winter (1998) 43-57

5. Devlin, K.: Infosense: Turning Information into Knowledge. W.H. Freeman and Company, New York (1999)

6. Grayson, C.J., O’Dell, C.: Mining Your Hidden Resources. Across the Board, 4 (1998) $23-28$

7. Hahn, J., Subramani, M.R.: A Framework of Knowledge Management Systems: Issues and Challenges for Theory and Practice. In: Proceedings of the International Conference on Information Systems, ICIS'2000, Brisbane (2000) 302-312

8. Handzic, M., VanToorn, C.: Penetration of KM Practices in a Non-Profit organisation: A Case of Academia. Working paper, UNSW (2002)

9. Hansen et al.: What's your strategy for managing knowledge?, Harvard Business Review, March-April (1999) 106-116

10. Huang, F.T. et al.: Quality Information and Knowledge. Prentice Hall, New Jersey (1999)

11. Kahn B., Stong D.M, Wang R.Y.: A Model for Delivering Quality Information as Product and Service. In: Proceedings of the International Conference on Information Quality, MIT, Boston (1997) 80-94

12. NOIE: http://www.noie.gov.au (accessed 30 November 2002)

13. Nonaka, I.: The Knowledge-Creating Company. In: Harvard Business Review on Knowledge Management, Harvard Business School Press, Boston (1998)

14. Nonaka, I., Takeuchi, H.: The Knowledge Creating Company: How Japanese Companies Create the Dynamics of Innovation. Oxford University Press, New York (1995)

15. Pederson, A.: http://john.curtin.edu.au/society (accessed 30 November 2002)

16. Polanyi, M.: The Logic of Tacit Inference. Philosophy, 1 (1966) 1-18

17. Quinn, J. B., Andeson, P., Finkelstein, S.: Managing Professional Intellect: Making the Most of the Best. Harvard Business Review, March-April (1996) 71-80

18. Shanks, G., Darke P.: Understanding Metadata and Data Quality in a Data Warehouse. Australian Computer Journal, November (1998)

19. Shanks, G., Tansley E.: Data Quality Tagging and Decision Outcomes: An Experimental Study. In: Proceedings of Decision Support in Internet Age Conference, DSIage2002, Cork (2002)

20. Standards Australia: Case Studies in Knowledge Management, Vol. 1, Standards Australia, Sydney (2002)

21. Standards Australia: Australian Standard: Records Management, Part 1\&2, Standards Australia, Sydney (2002)

22. Strong D.M., Lee Y.W., Wang R.Y.: Data Quality in Context. Communications of the ACM, 5 (1997) 103-110

23. Van Krogh, G.: Care in Knowledge Creation. California Management Review, 3 (1998) 133-153

24. Wand, Y., Wang R.: Anchoring Data Quality Dimensions in Ontological Foundations. Communications of the ACM, 11 (1996) 86-95 